\title{
Oak Ri
}




\section{DISCLAIMER}

This report was prepared as an account of work sponsored by an agency of the United States Government. Neither the United States Government nor any agency Thereof, nor any of their employees, makes any warranty, express or implied, or assumes any legal liability or responsibility for the accuracy, completeness, or usefulness of any information, apparatus, product, or process disclosed, or represents that its use would not infringe privately owned rights. Reference herein to any specific commercial product, process, or service by trade name, trademark, manufacturer, or otherwise does not necessarily constitute or imply its endorsement, recommendation, or favoring by the United States Government or any agency thereof. The views and opinions of authors expressed herein do not necessarily state or reflect those of the United States Government or any agency thereof. 


\section{DISCLAIMER}

Portions of this document may be illegible in electronic image products. Images are produced from the best available original document. 
The adoption of the Ann Arbor modificationl of the Rye staging

Table 1 here
Table 2 here system ${ }^{2}$ (Table 1) has permitted resolution of a number of problems encountered with the Rye staging system. Most important among these are the following: 1) Applicability of the new staging system to lymphoma as well as to Hodgkin's disease. 2) Consideration of an extra-lymphatic organ or site as a primary focus or as a direct extension from an adjacent lymphatic site 1,3; these presentations are more favorable than was thought heretofore and may, in fact, be curable $e^{3}$ 3) Separation of nodal from splenic disease, emphasizing the prognostic significance of the latter in preaicting hepatic involvement, particularly in Hodgkin's disease. 4) Emphasis on a dual system of stage designation according to Clinical Staging (CS) only and according to Pathologic Staging (PS); this permits comparison of all cases by clinical staging and comparison of biopsy proven sites by pathologic staging where applicable.

In an effort to stage patients as accurately as possible, it is important to search out sites of involvement by appropriate techniques and to document histologically, where feasible, that such involvement is indeed Hodgkin's disease. The Committee on Hodgkin's Disease Staging Procedures of the Ann Arbor Conference has urged that certain procedures be employed in staging petients so that the CS and PS might be more accurate and thus comparison between centers more easily accomplished than was heretofore possible 4 (Table 2).

Dr. Castellino has reviewed the place of conventional radiographic procedures, including lymphangiography, in the diagnostic evaluation of patients both at presentation and in relapse of disease. Dr. Hoffer and 
Dr. Peckham have presented data on the usefulness of Gallium 67 citrate scanning in patients with Hodgkin's disease.

In addition to the procedures already mentioned, special radiographic and radioisotope techniques may occasionaliy be useful in identifying sites of tumor involvement.

Azygography has been carried out in our institution by Dr. Klaus Ranniger" in more than a hundred patients with Hodgkin's disease or Iymphoma. Among these only a fey cases of lymphoma demonstrated displacement of the azygos vein indicating presumptive evidence of posterior mediastinal lymph node enlargement. In none of these patients vere conventionel radiologic studies positive. However, in none of the patients with Hodgkin's disease studied were the azygograms positive. The procedure cannot be recommended as routine in the work-up of patients with lymphoreticular neoplasms.

Dr. Paul Hoffer may have time in the workshop tomorrow to summarize his data on radioisotope scanning of bone marrow and bone. Suffice it to point out at this time that scanning of bone maxrow with Technetium 99 sulfur-colloid carried out during performance of liver-spleen scans may occasionally reveal involvement with Hodgkin's disease when radiologic evidence is lacking. Fluorinel8 bone scans may or may not be positive in such instances. Studies are currently in progress to correlate and compare these various techniques: The problems encountered in diagnosing lung infiltrates stimulated development of bronchial brushing and bronchial forceps biopsies as diagnostic procedures. Dr. John Fennessy of our Radiology Service in collaboration with Dr. Henry Rappaport and Dr. Daina Variakojis of our Iaboratory of Surgical Pathology are responsible for this project at the University of Chicago. 
A representative patient is a 16 year-old girl who presented in April 1969 at the University of Chicago Hospitals and Clinics with an eight-month history of pruritus, recent night sweats and weight loss. Physical examination was non-revealing. Radiologic examination of the chest showed a mediastinal mass and a contiguous infiltration in the anterior segment of here the right upper lobe (FIgure 1). Bronchial brushing and bronchial forceps biopsy showed Hodgkin's disease, nodular sclerosis (Figures 2, 3, 4). A complete staging work-up, including laparotomy and splenectomy, was negative. Consequently, a thoracotomy and a right upper- and right middle-lobectomy were performed. Final staging was Hodgkin's disease, NS CS II $\frac{\mathrm{B}}{\mathrm{E}}$ PS II $\mathrm{S}-\mathrm{H}-\mathrm{N}-\mathrm{M}-\mathrm{It} \mathrm{t}^{*}$ Postoperatively, the patient received megavoltage extended mantle therapy to a tumor dose of 4000 rads (completed August 1969): From April to November 1970, the patient received six cycles of combination chemotherapy with cytoxan (cyclophosphamide), Oncovin (vincristine sulfate), Procarbazine (Natulane $\mathbb{B}$ ) and Prednisone (COPP). She is in complete remission at this time.

Since then, additional experience has been gained in utilizing the technique of bronchial brushing for diagnosis of abnormalities seen in patients suspected or proven to have lymphoreticular neoplasms or in patients with Iymphoma suspected of having an opportunistic infection. The results obtained in these studies are summarized in Table 3 .

A few comments regarding the staging of patients following initial therapy or following relapse might be in order. The staging classification proposed in Ann Arborl specifies that both the clinical and the pathologic staging classification apply only to the patient at the time of disease 
presentation and prior to definitive therapy. The only exception might be that pathologic staging by laparotomy may be done following a course of treatment when symptoms (e.g., mediastinal or spinal cord compression) demand that treatment to the upper half of the body must be given first. It is obvious that the burden of thoroughness in the evaluation of the patient lies heavily on the first team of physicians who stage the patient. Unfortunately, patients are often seen following errors in clinical or pathologic staging or following errors in therapeutic management. Reassessment and determination of correct stage may be helpful in selected cases. In aodition, a significant number of patients come to the physician in relapse and require careful evaluation to determine treatment strategy. In order to adhere to the recommendations proposed at this meeting (vide infra: Report on Workshop Session: Clinical Evaluation, Staging and Prognosis), we have used the following designations for patients in relapse: Iocal recurrence: a recurrence in an area previously treated; regional recurrence: a recurrence outside the previously treated area, however confined to the same siae of the diaphragm where disease was found initially; transdiaphragmatic recurrence: occurrence of disease in lymph nodes (or in spleen) but on the other side of the diaphragm than originally noted; and extralymphatic recurrence: appearance of disease in extra-nodal or extra-splenic sites.

During the past 3 years we have had the opportunity to stage 18 patients who have had previous clinical staging 4 months to 11 years prior to being seen by us. The initial status, including clinical stage, therapy and result are shown in Table 4. Two of the 18 patients had pathologic staging 3 years (Case $\frac{116}{\pi}$ ) and 1 year (Cast 49 ) prior to the second staging 
proceaure. In rive cases ( $/$ th $, 4,7,15,17$ ), intercurrent events led to recurrences and additional therapy was given (Table 4).

The case of a 24 year-old woman (Case 什16) seen for the first time at another medical center illustrates problems encountered in reassesment of patients in relapse. In August 1968 the patient presented with painless left supraclavicular lymphadenopathy. She had no symptoms. Biopsy showed Hodgkin's disease, nodular sclerosis. Clinical stage was CS III-A and pathologic stage, PS III $\mathrm{S}+\mathrm{H}-\mathrm{IV}+\mathrm{M}-$. The patient received total nodal radiotherapy (Van de Graaff generator, 4300 rads tumor dose) and went into complete remission. In May 1969 the patient developed a nephrotic syndrome which improved on steroid therapy. In June I969 she had an episode of herpes zoster which healed rapialy. Beginning December 1970 she complained of fever and anorexia. Physical examination, routine biood tests, liver function tests, radiologic examinations (including chest film, gastro-intestinal series, pyelogram and lymphangiogram) and liver biopsy were negative. The patient was then transferred to our hospital for lurther work-up. 99Tc liver-"spleen" scan showed a single filling defect in the liver and no spleen uptake;

Fig. 5 here

Fig. 6 here however, the Gallium67 scan revealed a left upper quadrant mass (Figure 5). Repeat $67 \mathrm{Ga}-s$ can confirmed this observation. In view of these findings our impression was that the patient had an extra-lymphatic recurrence. A second staging laparotomy was performed. This revealed massive peripancreatic lymph nodes in the position indicated by the Gallium67 scan (Figure 6); liver biopsies showed Hodgkin's disease. The histologic pattern was nodular sclerosis. The patient was placed on cyclic combination chemotherapy with COPP and entered a complete remission in September 1971. She has been maintained on BCNU (bis-chloroethyl-nitrosourea) at monthly intervals to the present time. 
Among the patients (Table 4 ), one case ( $\#_{1}$ ) originally staged CS III-A was found to have been treated incompletely with a mantle only; our assessment was compatible with residual infradiaphragmatic disease in lymph nodes being present 2 years later. Pathologic staging revealed findings strongly suggestive of extra-Iymphatic extension ( $\mathrm{S}-\mathrm{H}+\mathrm{N}+\mathrm{M}-$ ). The patient was given total nodal radiotherapy followed by 6-cycle chemotherapy with COPP. She has been free of disease 15 months. Two patients were thought to have true recurrences only: in one (Case $\mathbb{H}_{2}$ ), laparotomy was négative; in the other (Case \#3), an unsuspected transdiaphragmatic recurrence was found. Eight patients (Cases $\frac{14}{14}, 5,6,7,8,9,10,11$ ) were thought to have recurrences above and/or below the diaphragm: In each instance, the laparotony findings supported the clinical impression. Three patients appeared to have developed

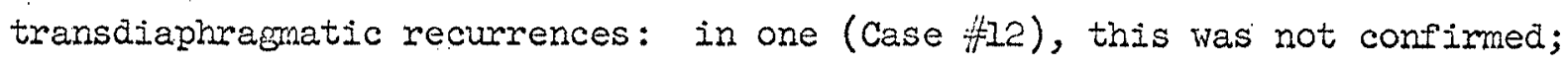
but in two (Cases $\# 13$ and 14), it was proven by laparotomy and splenectomy. Four patients were suspected of having extra-Iymphatic extensions: in three cases (t/ 15,16 and 18) this was confirmed; in one, it could not be proven (Case $\# 27$ ).

In summary, of the 7 negative laparotornies, one resulted in a change in stage you TDR to RR and only a mantle treatment was given (Case \#I2). Of the 11 positive laparotomies, 3 revealed unsuspected findings: CS III $\rightarrow E L$

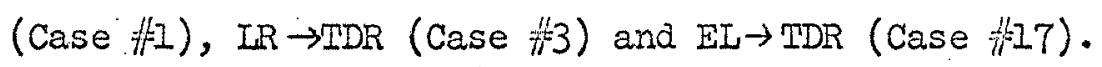

In all instances, therapeutic measures could be based on information obtained from the surgical staging. These are summarized for each patient in Table 4. There was no post-operative morbidity or mortality in this group of patients. It is concluded that meticulous pathologic staging, including laparotomy and splenectomy when indicated, is userul and feasible in the work-up of patients with Hodgkin's disease in relapse. 


\section{REFERENCES}

I. Carbone, P. P., Kaplan, H. S., Musshof:, K., Smithers, D. W., and Tubiana, M. Report of the Committee on Hodgkin's Disease Staging Classification. Cancer Res. 31:1860-1861, 1971.

2. Rosenberg, S. A. Report of the Comrnittee on the Staging of Hodgkin's Disease. Cancer Res. 26:1310, 1966.

3. Musshoff, K. Prognostic and Therapeutic Implications of Staging in Extranodal Hodgkin's Disease. Cancer Res. 31:1814-1821, 1971.

4. Rosenberg, S. A., Boiron, M., DeVita, V.T., Jr., Johnson, R. E., Lee, B. J., Ultnann, J. E., and Vianonte, M., Jr. Report of the Committee on Hodgkin's Disease Staging Procedures. Cancer Res. 31:1862-1863, 1971. 


\section{Legends}

Figure 1. X-ray of chest of 16 year-old girl with eight-months history of pruritus and recent night sweats and weight loss showing mediastinal mass and a contiguous infiltration in the anterior segment of the right upper lobe.

Figure 2. Bronchial brushing of right upper lobe.

Figure 3. Bronchial forceps biopsy of right upper lobe.

Figure 4. Track of bronchial forceps catheter as seen in histologic section of tumor in lobectomy specimen.

Figure 5. The $67 \mathrm{Ga}-\mathrm{scan}$ (A) reveals a left upper quadrant mass. The 99Tc Iiver-"spleen" scan (B) fails to visualize spleen.

Figure 6. In situ view of the operative field. The costal arch is shown cephalad. Massive peripancreatic lymph nodes are seen in the position indicated by the $67_{\text {Ga-scan. }}$ 


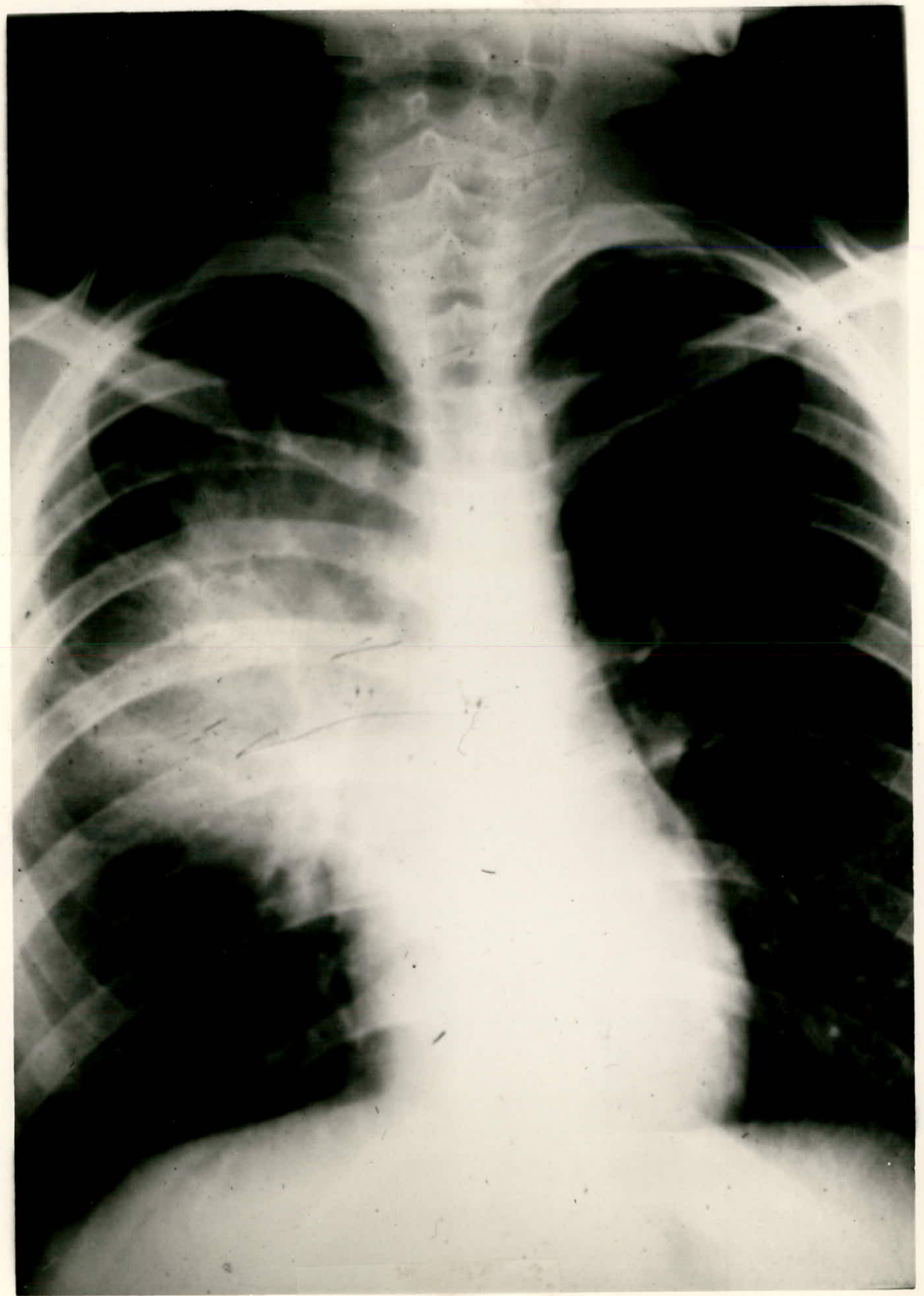

Figure 1. X-rey of chest of 16 year-old gixl with eightmonthis history of pruritus and recent night sweats and weight loss showing nediastinal mass and contiguous infizration in the anterion segnent of the right upper Iobe. 


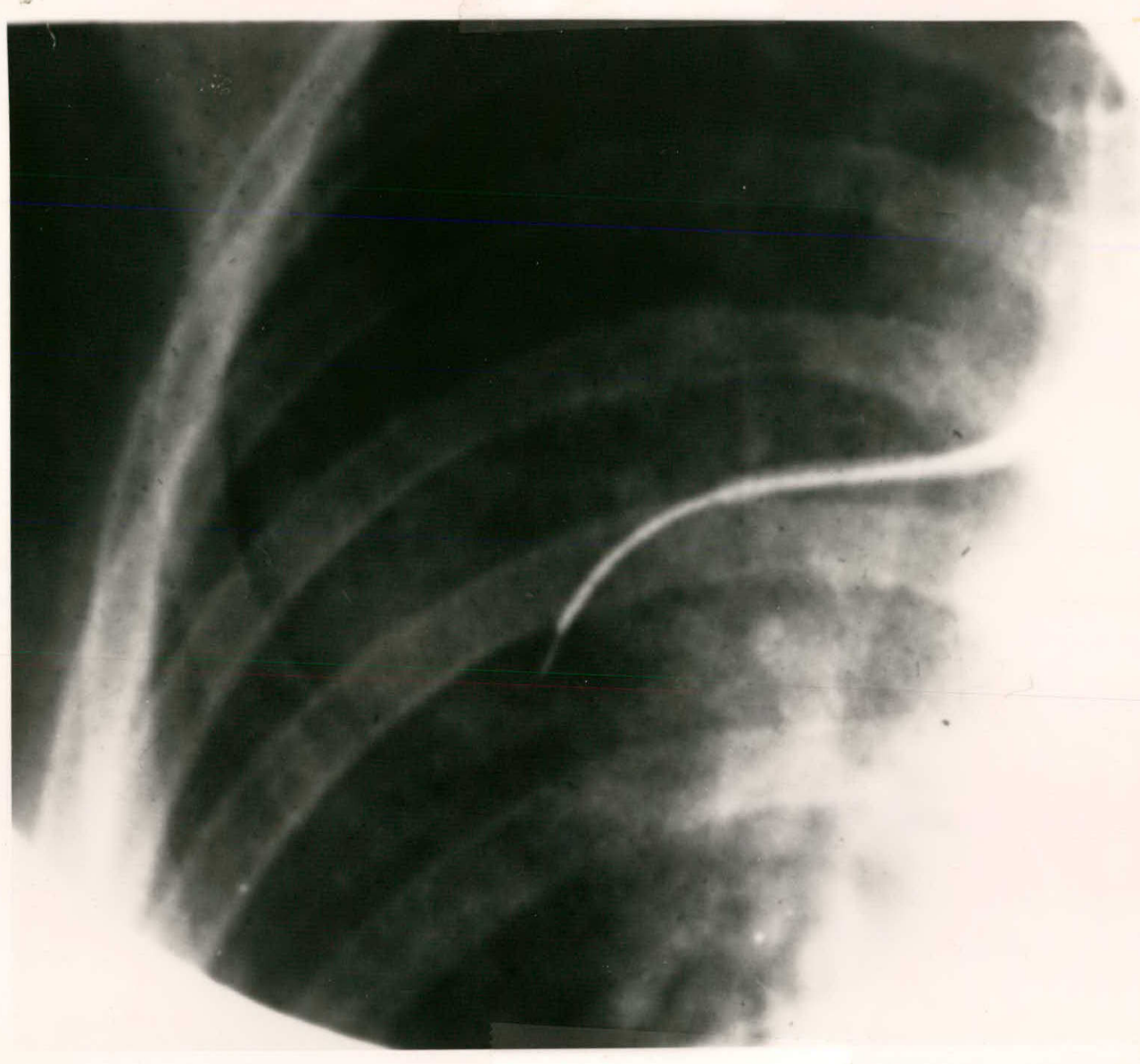

Figure 2. Bronchial brushing of right upper lobe. 


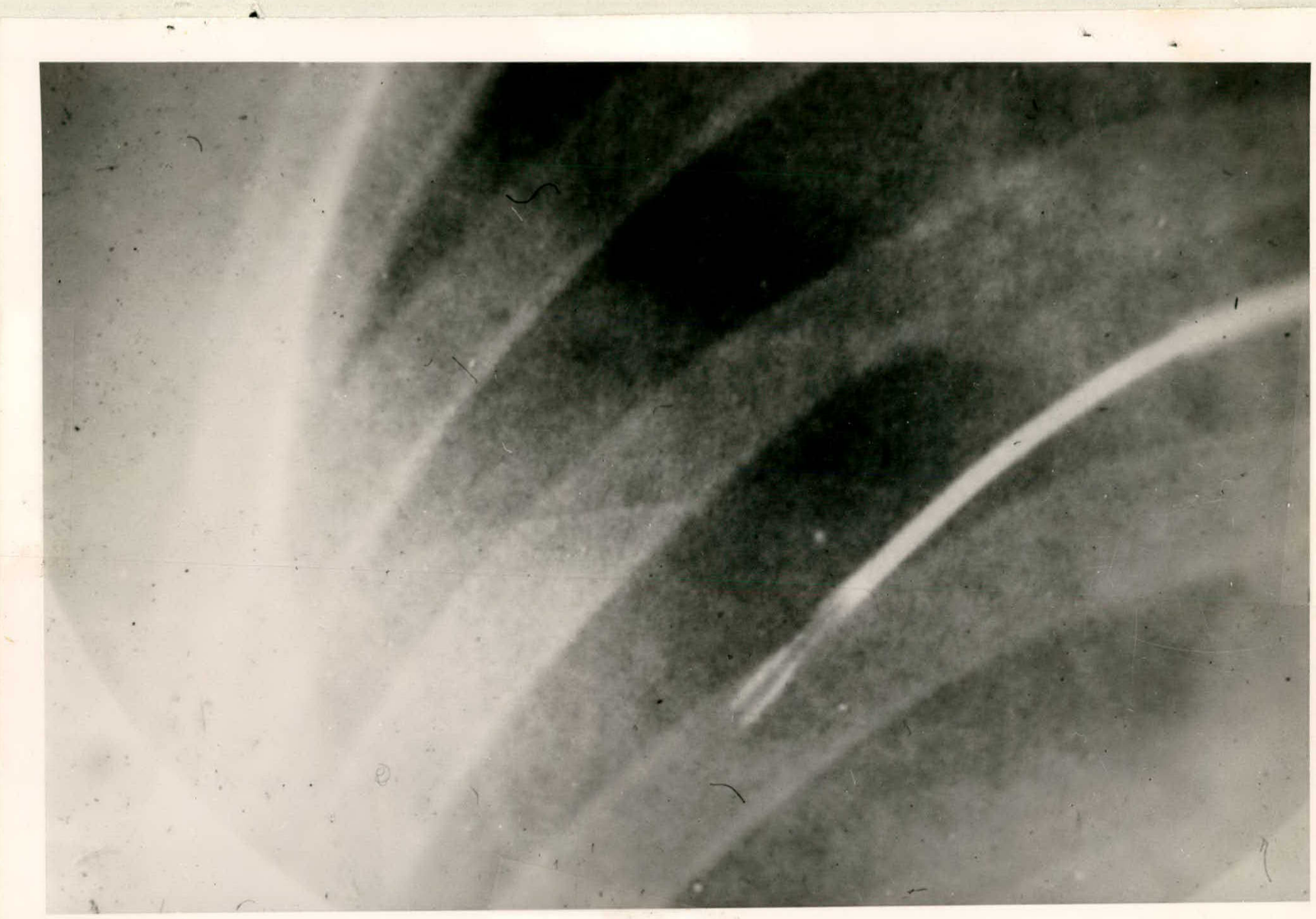

Figure 3. Bronchiai forceps biopsy of right upper lobe. 


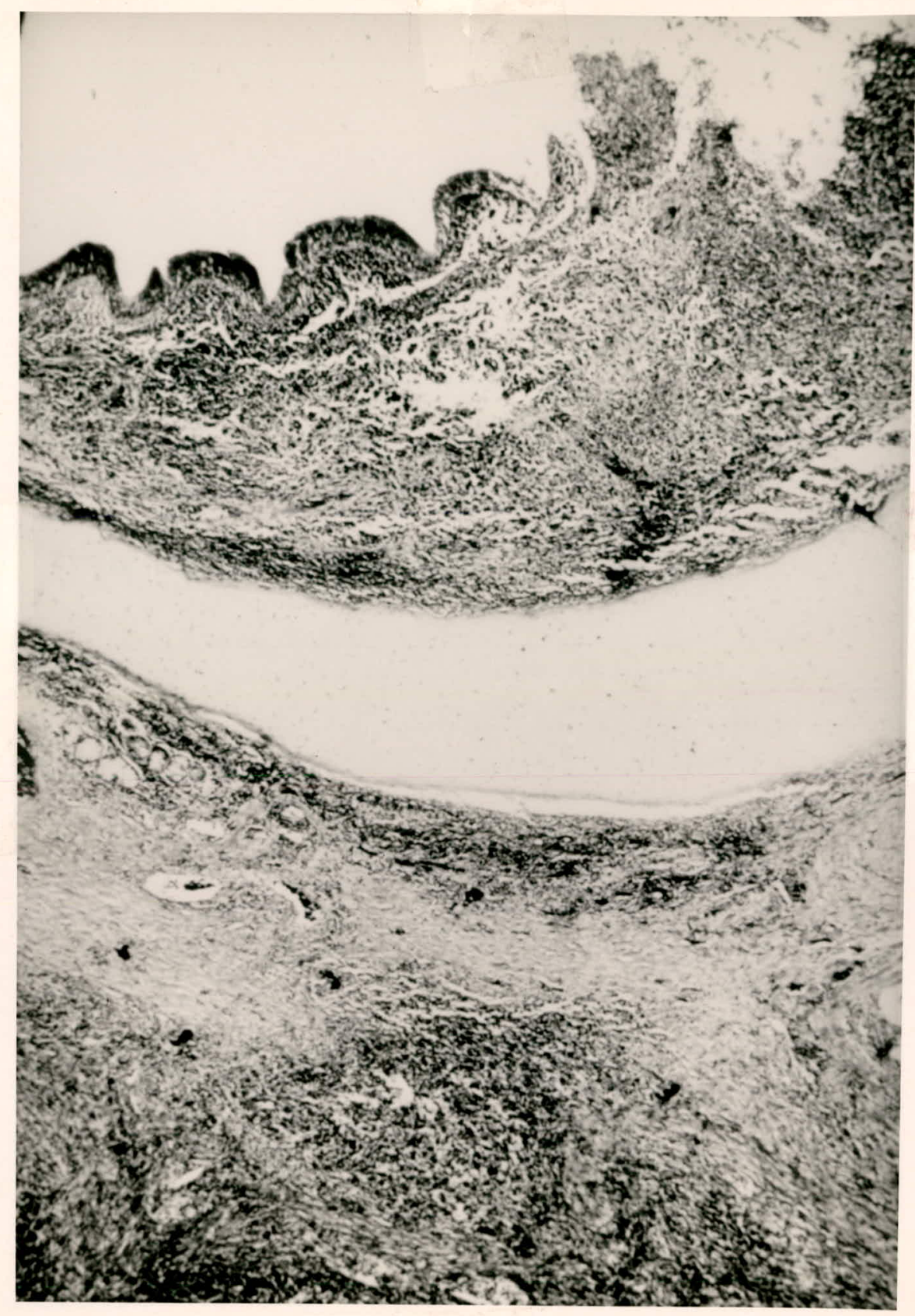

Figure 4. Track of bronchial forceps catheter as seen in histologic section of tumor in lobectomy specimen. 


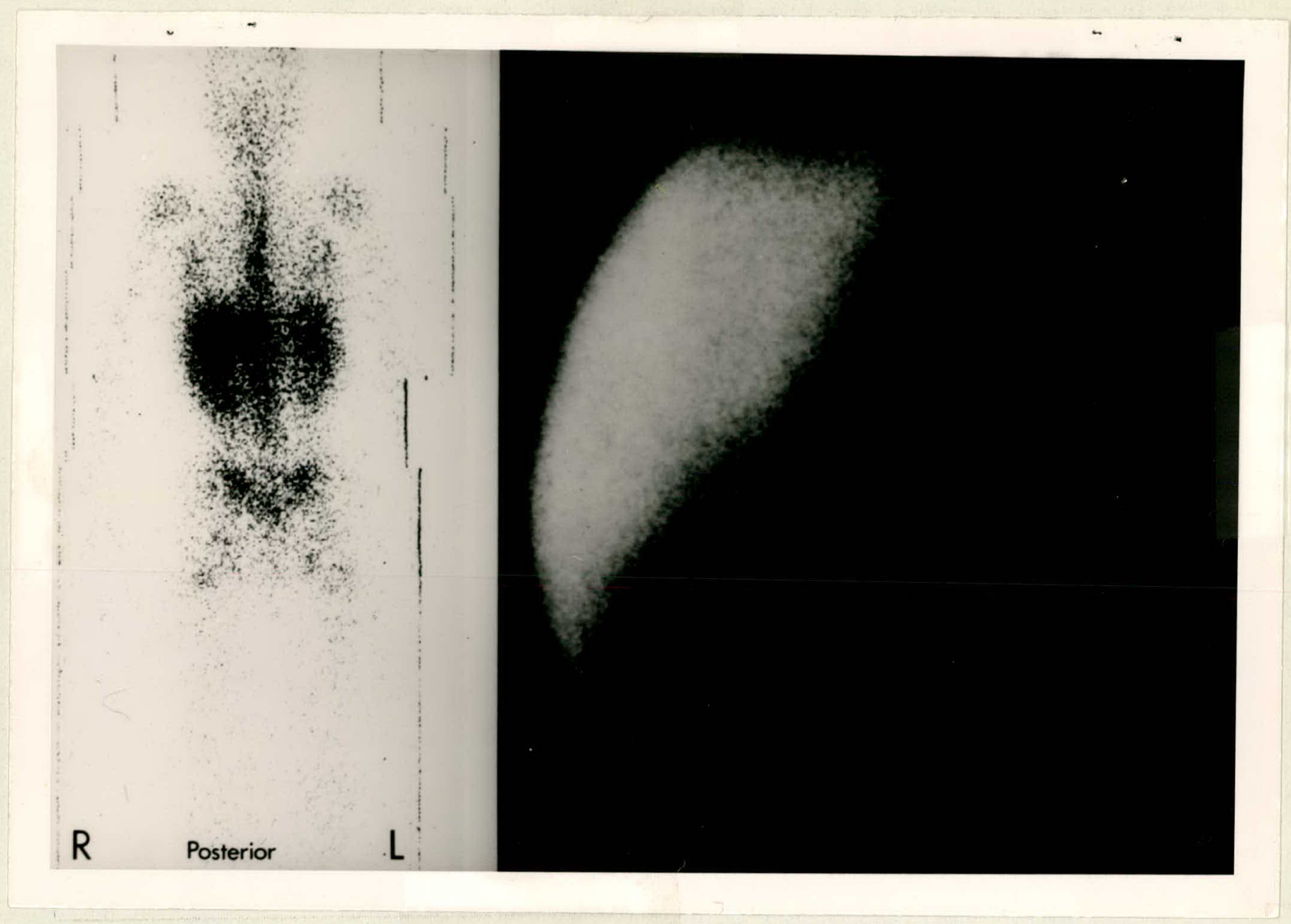

Figure 5. The $67 \mathrm{Gamsen}$ (A) reveals a left upper quadrant mass. me 99me Liver-"spleen" scan (B) fails to visualize spleen. 


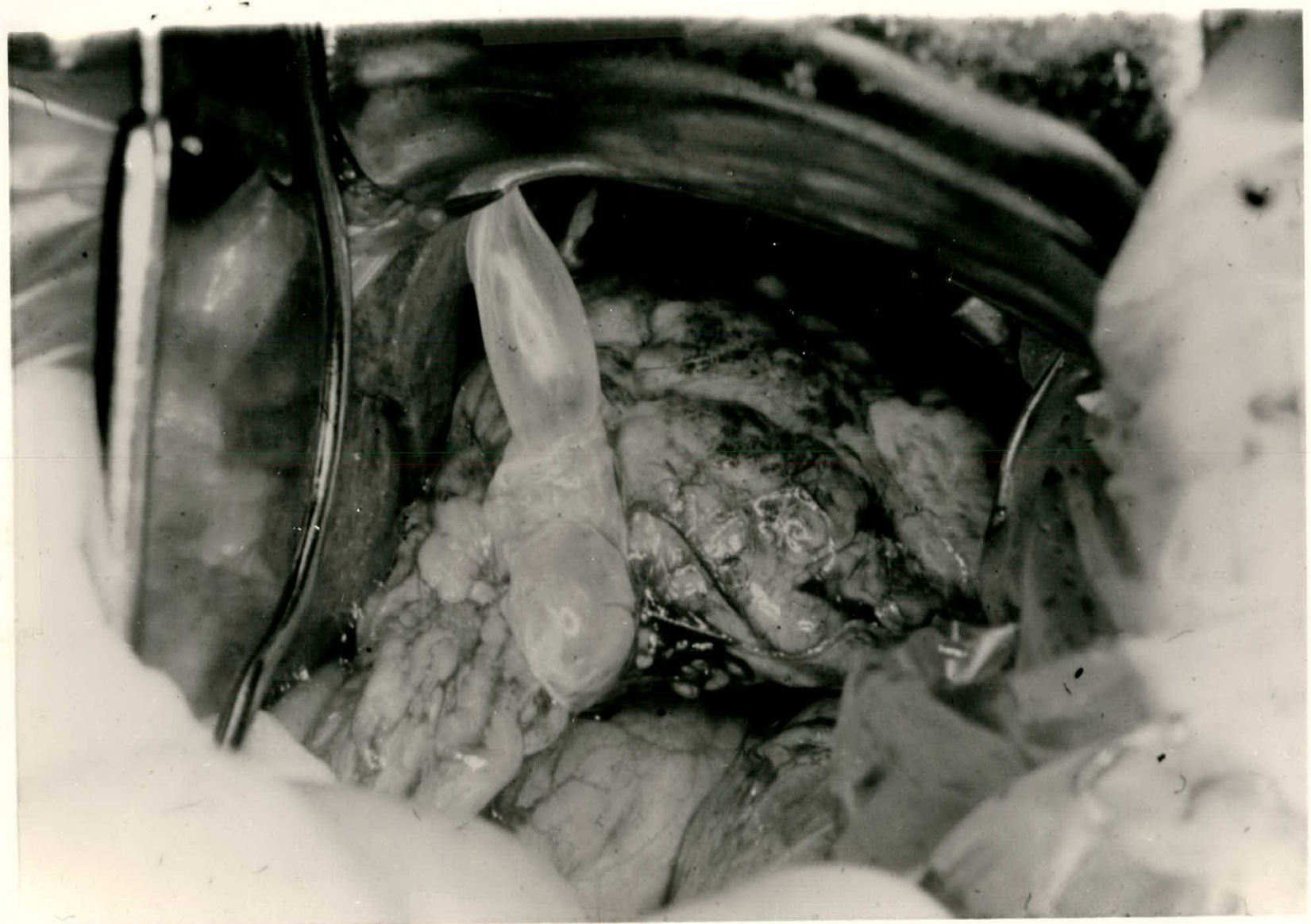

Rigure 6. Im situ view of the operative tield. The costal axch is shown cephaiad. Massive pexipancreatic lymph nodes are seen in the position indicated by the $67 \mathrm{Gamsan}$. 
Table 1. HODGKIN'S DISEASE: ANN ARBOR MODIFICATION OF RYE STAGING SYSTEM (1971)

Stage I: Involvement of a single lymph node region ( $I$ ) or of a single extra-lymphatic organ or sige $\left(I_{E}\right)$.

Stage II: Involvement of two or more lymph node regions on the same side of the diaphragm (II) or localized involvement of extra-lymphatic organ or site and of one or more lymph node regions on the same side of the diaphragm ( $\left(I_{E}\right)$. Optional recommendation: Number of node regions involved indicated by subscript (e.g., II $(3)$ ).

Stage III: Involvement of lymph node regions on both sides of the diaphragm (III), which may also be accompanied by localized involvement of extra-Iymphatic organ or site (IIIE), or by involvement of the spleen (IIIS) or both (IIISE).

Stage IV: Diffuse or disseminated involvement of one or more extra-lymphatic organs or tissues with or without associated lymph node enlargement. The reason for classifying the patient as stage IV should be identified further by defining site by symbols.

In Hodgkin's disease, all patients are subclassified $A$ or $B$ to indicate the absence or presence, respectively, of 1) unexplained weight loss of more than $10 \%$ of their body weight; 2) unexplained fever with temperatures above $38^{\circ}$; 3) night sweats.

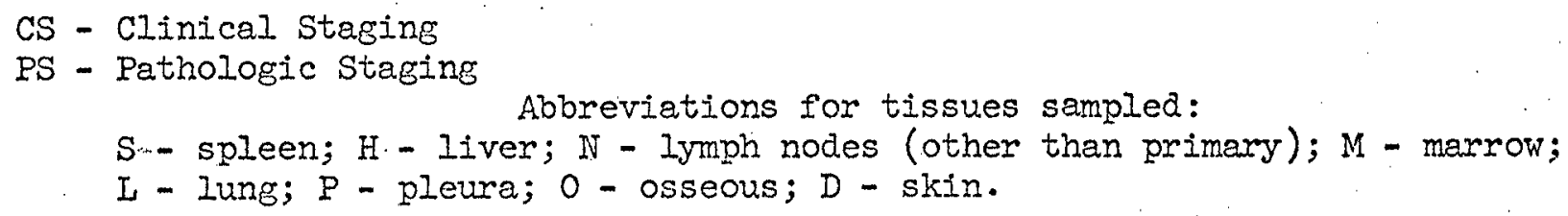
Staging Classification Examples
CS I-A PS I $\mathrm{S}-\mathrm{H}-\mathrm{N}-\mathrm{M}-$
CS $I I-A_{(3)}$ PS $I I I_{S+H-N-M-} I$
CS III-B PS IV $\mathrm{S-H+M-}$
CS IV-B ${ }_{\text {IH }}$ PS IV $I_{\mathrm{H}+\mathrm{M}-}$
Implies clinical stage I without symptoms and patho- logic stage $I$; and negative spleen following splenectomy, liver biopsy negative, additional node biopsy negative and marrow biopsy negative.




\section{Table 2. RECOMMENDATIONS ON STAGING PROCEDURES}

\section{A. Required Evaluation Procedures}

1. Adequate surgical biopsy, reviewed by hematopathologist

2. Detailed history (?fever, sweating, pruritus, and weight loss)

3. Complete physical examination with attention to lymphadenopathy, Waldeyer's ring, liver, and spleen; and bone tenderness

4. Laboratory studies: CBC, platelet count, ESR, serum alkaline phosphatase level Evaluation of renal function and liver function

5. Radiologic studies:

a. Chest roentgenogram (P.A. and lateral views)

b. Intravenous pyelogram

c. Bilateral lower extremity lymphangiogram

d. Skeletal survey, esp. thoraco-lumbar vertebrae, pelvis, proximal extremeties, and areas of bone tenderness and/or pain.

B. Required Evaluation Procedures under Certain Conditions

1. Whole chest tomography, if abnomality on chest roentgenogram

2. Inferior cavography for equivocal lymphogram or pyelogram

3. Bone marrow biopsy, by a needle or open surgical technique if a. Serum alkaline phosphatase elevated

b. Unexplained anemia or other blood count depression c. Roentgenographic or scintigraphic evidence of osseous disease

d. Generalized disease of stage III category or greater

4. Exploratory laparotomy and splenectomy, if management decisions will depend on the identification of abdominal disease.

c. Useful Ancillary Procedures not Definitive for Diagnosis

1. Skeletal scintigrams

2. Hepatic and spleen scintigrams

3. Serum chemistries, including calcium and uric acid

4. Estimate of patient's delayed hypersensitivity

D. Procedures and Tests Promising for Clinical Study at Selected Centers but Experimental at this Time

1. Whole body Gallium 67 and Selenium 75 scintigrams

2. Determinations of serum iron and iron binding capacity, copper and ceruloplasmin, zinc, haptoglobin, fibrinogen, alpha-2-globulin; as well as urinary hydroxyproline, leukocyte alkaline phosphatase, absolute lymphocyte count, antibodies to Epstein-Barr virus, human lymphocyte antibody typing. 
Table 3. BRONCHIAL BRUSHING

$$
\begin{aligned}
& \text { Number of } \\
& \text { Patients }
\end{aligned} \quad \begin{gathered}
\text { Pathologic Finding } \\
\text { Broven Bx-negative }
\end{gathered}
$$

Hod.gkin's Disease

Iymphoma

Opportunistic Infections

Pneumocystis Carinii

Varicelia

Nocardia

Aspergillus
6

3

5

1 .

1

1
3

1

4. 1

10

10

10
3

2

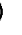

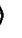

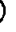

Courtesy Drs. J. Fennessy, H. Rappaport and D. Variakojis 
Table 4. STAGING HODGKIN'S DISEASE AFTER INITIAL THERAPY

\begin{tabular}{|c|c|c|c|c|c|c|c|c|}
\hline \multirow[b]{2}{*}{$\begin{array}{l}\text { Case No. } \\
\text { Age/Sex }\end{array}$} & \multicolumn{3}{|c|}{ Initial Status } & \multirow{2}{*}{$\begin{array}{l}\frac{\text { Evolution }}{\text { Intercurrent }} \\
\text { Events \& Therapy }\end{array}$} & \multirow{2}{*}{$\begin{array}{r}\text { Interval } \\
\text { btw First } \\
\text { staging o } \\
\text { Reassessment } \\
\end{array}$} & \multicolumn{3}{|c|}{ Reassessment } \\
\hline & $\begin{array}{c}\text { C. S. } \\
\text { before } \mathrm{RX}\end{array}$ & Therapy & Result & & & C. S. & P. S. & Therapy \\
\hline $\begin{array}{l}1 . \\
23 / \mathrm{F}\end{array}$ & III-A MC & ${ }^{60} \mathrm{Co}-\mathrm{MX} 4500$ & $\begin{array}{c}\text { CR } \\
\text { Chest }\end{array}$ & --- & 2.yrs. & $\begin{array}{c}\text { III-A } \\
\text { (Abdomen not } \\
\text { prev. treated) }\end{array}$ & $\mathrm{S}-\mathrm{H}+\mathrm{N}+\mathrm{M}-$ & $\begin{array}{c}\text { VAG-TN } 4000 \\
+ \\
\text { COPP }\end{array}$ \\
\hline
\end{tabular}

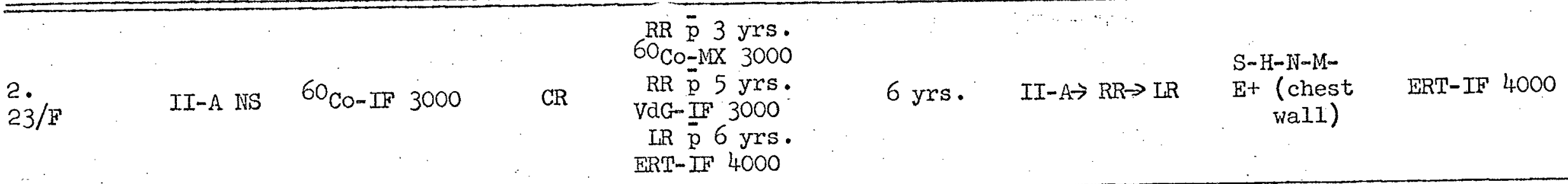

\begin{tabular}{|c|c|c|c|c|c|c|c|c|}
\hline $34 / 5$ & $I I-B N S$ & ${ }^{60} \mathrm{Co}$-IF 4500 & PR & $\cdots$ & 4 mos. & $I I-B \rightarrow I R$ & $\mathrm{~S}+\mathrm{H}-\mathrm{N}-\mathrm{M}-$ & VdG-EM 4000 \\
\hline $46 / \mathrm{F}$ & I-A NS & $\mathrm{kv}-\operatorname{IF} 3000$ & $\mathrm{CR}$ & $\begin{array}{l}R R \bar{p} 2 \text { yrs. } \\
k v-I F 2000 \\
I R \bar{p} 5 \mathrm{yrs} . \\
k V-I F 2200\end{array}$ & 9 yrs. & $I-A \rightarrow R R \rightarrow R R$ & $\mathrm{~S}-\mathrm{H}-\mathrm{N}-\mathrm{M}-$ & VaG-EM 4000 \\
\hline
\end{tabular}

\begin{tabular}{|c|c|c|c|c|c|c|c|c|}
\hline $\begin{array}{l}5 \cdot \\
24 / F\end{array}$ & III-A NSS & VdG-TN 3000 & $\mathrm{CR}$ & $-\cdots$ & 5 yrs. & III-A $\rightarrow$ Rec & $\mathrm{S}+\mathrm{H}-\mathrm{N}+\mathrm{M}-$ & $\mathrm{COPP}$ \\
\hline $\begin{array}{l}6 . \\
42 / M\end{array}$ & III-A MC & VaG-TN 3500 & $\mathrm{CR}$ & $-\infty$ & $5 \mathrm{yrs}$ & III $-A \rightarrow$ Rec & $\mathrm{S}+\mathrm{H}-\mathrm{N}+\mathrm{M}-$ & VdG-TF, 4000 \\
\hline $\begin{array}{l}7 \\
20 / F\end{array}$ & I-A INS & ${ }^{60} \mathrm{Co}-$ IF 4000 & $\mathrm{CR}$ & $\begin{array}{l}\mathrm{RR} \overline{\mathrm{p}} 1 / \mathrm{t} \mathrm{yrs} \text {. } \\
60 \mathrm{Co}-\mathrm{IF} 3000 \\
\mathrm{TDR} \overline{\mathrm{p}} 3 \frac{1}{\mathrm{~T}} \mathrm{yrs} . \\
60 \mathrm{Co}-\mathrm{IF} 3500\end{array}$ & 4 yxs. & $I-A \rightarrow T D R \rightarrow R e c$. & $\mathrm{S}+\mathrm{H}-\mathrm{N}+\mathrm{M}-$ & $\begin{array}{c}\mathrm{VQG}-\mathrm{TN} \\
+ \\
\operatorname{COPP}\end{array}$ \\
\hline
\end{tabular}

\begin{tabular}{|c|c|c|c|c|c|c|c|c|}
\hline $24 / F$ & $I I-A$ NS & $\begin{array}{l}\mathrm{kV} \text {-IF } 2400 \\
\mathrm{kV}-\text { IF } 2000 \\
60 \mathrm{Co}-\mathrm{IF} 3800\end{array}$ & $\mathrm{CR}$ & $-\infty$ & 3 yrs. & $I I-A \rightarrow R R$ & $\begin{array}{c}\mathrm{S}-\mathrm{H}-\mathrm{N}-\mathrm{M}- \\
:\end{array}$ & $\mathrm{VdG}-\mathrm{MX} \quad 4000$ \\
\hline
\end{tabular}




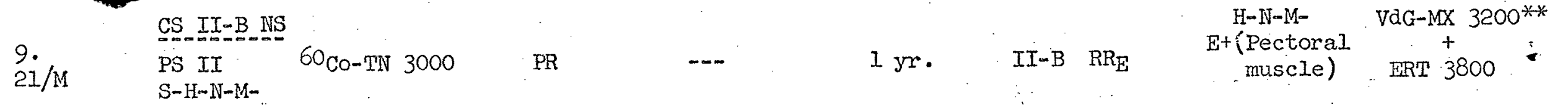

\begin{tabular}{|c|c|c|c|c|c|c|c|c|}
\hline $\begin{array}{l}10 \cdot \\
29 / F\end{array}$ & $I=A$ INS & $k V-I F 2300$ & $\mathrm{CR}$ & $-\infty$ & 3 yrs. & $I-A \rightarrow I R \& R R$ & $\mathrm{~S}-\mathrm{H}-\mathrm{N}-\mathrm{M}-$ & VdG-IF 4000 \\
\hline $\begin{array}{l}11 . \\
49 / F\end{array}$ & $I I_{\mathrm{E}^{-A}} \mathrm{NNS}$ & $\begin{array}{l}60 \mathrm{CO}-\mathrm{EF} \\
2500-3350\end{array}$ & $\mathrm{CR}$ & $-\infty$ & 3 yrs. & $I I_{E}-A \rightarrow I R \& R R$ & $\mathrm{~S}-\mathrm{H}-\mathrm{N}-\mathrm{M}-$ & $\begin{array}{ll}V \alpha G-M X & 4000 \\
\text { ERT-IF } 1400\end{array}$ \\
\hline$\frac{12}{26 / M}$ & $I I=A$ IVS & $\begin{array}{l}\mathrm{kv}-\text { IF } 550 \\
60 \mathrm{Co}-\text { IF } 1000\end{array}$ & PR & --- & $11 \mathrm{yrs}$ & $I I-A \rightarrow T D R$ & $\mathrm{~S}-\mathrm{H}-\mathrm{N}-\mathrm{M}-$ & VaG-MX 4000 \\
\hline $\begin{array}{l}13 \cdot \\
16 / \mathrm{M}\end{array}$ & I-A NS & $V a G-M X \quad 4000$ & $\mathrm{CR}$ & --- & 3 yrs. & $I-A \rightarrow T D R$ & $\mathrm{~S}-\mathrm{H}-\mathrm{N}+\mathrm{M}-$ & $V d G-Y 4000$ \\
\hline $\begin{array}{l}14 \\
23 / \mathrm{M}\end{array}$ & I-A INS & ${ }^{60} \mathrm{CO}-\mathrm{EF} 3200$ & $\mathrm{CR}$ & $\cdots$ & 2 yrs. & $I-A \rightarrow L R \& T D R$ & $\mathrm{~S}+\mathrm{H}-\mathrm{N}+\mathrm{M}-$ & $\begin{array}{c}\mathrm{VaG}-\mathrm{TN} \\
+ \\
\text { ERT-IF } 12000\end{array}$ \\
\hline
\end{tabular}

\begin{tabular}{|c|c|c|c|c|c|c|c|c|}
\hline $\begin{array}{l}15 \\
28 / F\end{array}$ & $\operatorname{III}_{S}-\mathrm{A} N \mathrm{NS}$ & VdG-TN 4000 & $\mathrm{CR}$ & $\begin{array}{c}R R \bar{p} \perp y r . \\
V d G=I F 4000 \\
L R \quad \bar{p} 4 \text { yrs. } \\
V a d=I F \quad 3500\end{array}$ & $4 \mathrm{yrs}$ & $\operatorname{III}_{\mathrm{S}}-\mathrm{A} \rightarrow \mathrm{ReC} \rightarrow \mathrm{EI}$ & $\begin{array}{l}\mathrm{S}-\mathrm{H}-\mathrm{N}+\mathrm{M}- \\
\mathrm{D}+\end{array}$ & $\begin{array}{l}V A G-I F \quad 4000 * \% * \% \\
\text { ERT-IF } 4000\end{array}$ \\
\hline $\begin{array}{l}16 \\
24 / F\end{array}$ & $\begin{array}{l}\text { CS_EFANS } \\
\text { PS III } \\
\mathrm{S}+\mathrm{H}-\mathrm{IN}+\mathrm{M}-\end{array}$ & VdG-TN 4300 & $\mathrm{CR}$ & $-\infty$ & $3 \mathrm{yrs}$. & $\operatorname{III}_{S}-\mathrm{A} \rightarrow \mathrm{EL}$ & $\mathrm{H}+\mathrm{N}+\mathrm{M}-$ & COPP \\
\hline $\begin{array}{l}17 \\
26 / 5\end{array}$ & I-A INS & $\mathrm{kv}-$ IF 3600 & $\mathrm{CR}$ & $\begin{array}{l}\text { TDR } \overline{\mathrm{p}} 3 \mathrm{mos} . \& \\
\text { IR's; } \mathrm{kV}-\mathrm{IF} \\
1000-3600\end{array}$ & 3:yrs. & $I-A \rightarrow T D R \rightarrow E L$ & $\mathrm{~S}+\mathrm{H}-\mathrm{N}+\mathrm{M}-$ & $\begin{array}{c}\text { VdG-TN } 4000 \\
+ \\
\text { COPP }\end{array}$ \\
\hline $\begin{array}{l}18 \cdot \dot{4} \\
48 / \mathrm{F}\end{array}$ & $I I_{S}-B$ IIS & ${ }^{60} \mathrm{CO}-\mathrm{IF} 4000$ & PR & --- & 6 mos. & $\mathrm{II}_{\mathrm{S}}-\mathrm{B} \rightarrow \mathrm{EL}$ & $\mathrm{S}+\mathrm{H}+\mathrm{N}+\mathrm{M}-$ & $\mathrm{VLB}+$ Pred. \\
\hline
\end{tabular}




$$
\begin{aligned}
& \text { CS }=\text { Clinical Stage } \\
& \text { PS }=\text { Pathologic Stage } \\
& \text { MC }=\text { Mixed Cellularity } \\
& \text { NS }=\text { Nodular Sclerosis }
\end{aligned}
$$

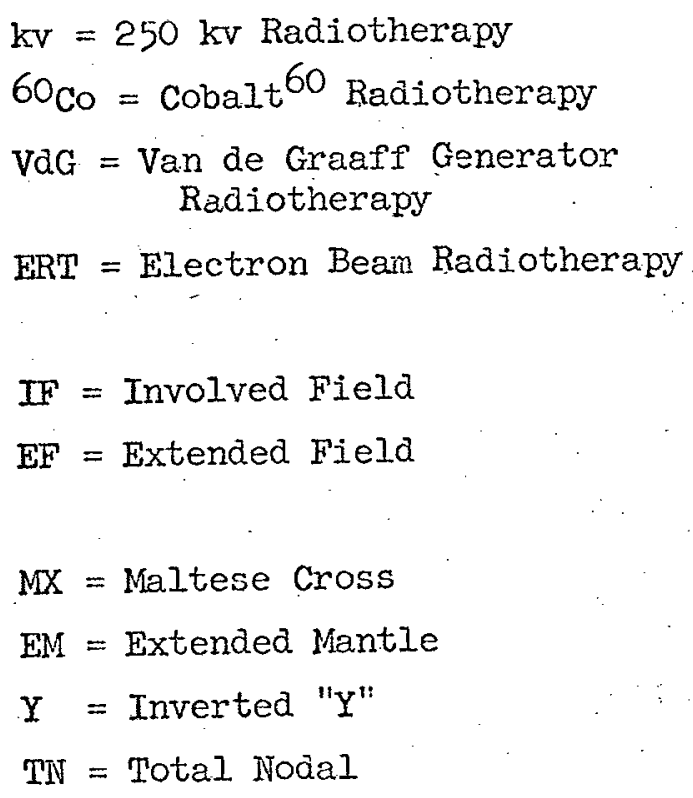

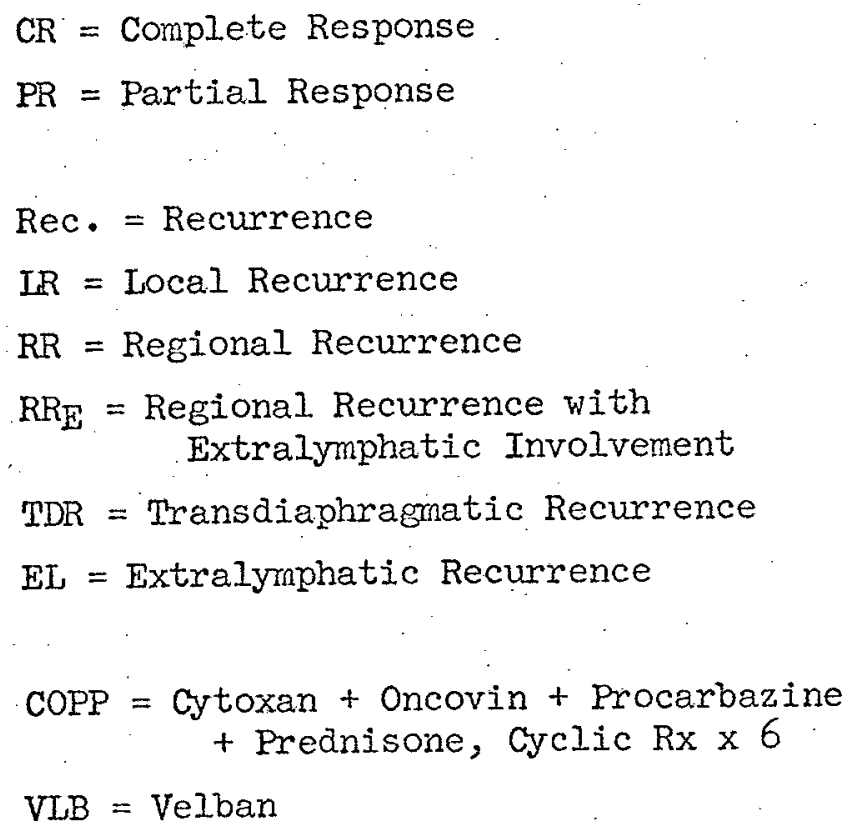

*The time of the intercurrent events is calculated from the initial therapy. * *Patient refused completion of planned radiotherapy. ***Chemotherapy for EL not applicable because of documented inactive coccidioidomycosis 